\title{
— Strategy Development for a Mental Health and Psychological support Knowledge Hub
}

\author{
Needs Assessment of Caregivers \\ working with Refugees in Fragile Contexts \\ in the Arab Region
}




\section{Acknowledgements}

This needs assessment report has been developed by Lebanon Support in the frame of an Arab Resource Collective project «Strategy Development for a Mental Health and Psychological support Knowledge Hub». The Lebanon Support team would like to extend their thanks to the Arab Resource Collective for providing our team with the opportunity to collaborate on this topic. We are also grateful to the participants of the in-depth interviews that took place in November 2016 and to the participants to the two day workshop organized by ARC in the 6 of December 2016 for their insightful feedback and discussion.

\section{Report Team}

\section{For Lebanon Support}

Principal Investigator, author of the report: Zeina Zerbé

Experts: Nathalie Der-Sahaguian Ayvazian, Dr. Mayssa' El-Husseini, Rose-Marie Nassif Abou Assaf

ICT web developers for monkey survey: Walid Abou Saifan, Ali Najjar

Editors: Amreesha Jagarnathsingh, Rola Saleh

Director Of Publications: Léa Yammine

Head of Research: Dr. Marie-Noëlle AbiYaghi

\section{For the Arab Resource Collective}

Regional Mental Health Program coordinator: Cosette Maalouf

General coordinator: Dr. Ghassan Issa

The views expressed in this publication are solely those of the author(s) and do not necessarily reflect the views of Lebanon Support, the Arab Resource Collective, or their partners. Beirut, December 2016.

Keywords: Mental Health, Mental Health providers in the Arab World, Psychosocial interventions, Psychological needs, Syrian refugees, Refugees. 


\section{Abstract}

The objective of the report is to identify the psychosocial impact and needs of humanitarian actors working with refugees in Syria, Lebanon, Jordan, Egypt, North Iraq and Palestine. The research approach was based on mixed methods combining quantitative and qualitative methodologies. A closed questionnaire was disseminated online on the one hand, and on the other, in-depth interviews were conducted with selected candidates. Findings reveal important transmission of beneficiaries' traumatic experience to the caregivers that suffer from light to severe psychosomatic symptoms, psychosocial disturbances, and vicarious traumatization. The needs highlighted entail institutional measures, working conditions, and psychological accompaniment to be insistently implemented in order to assure the humanitarian actors' mental and physical wellness. 


\section{Table of Contents}

1.1. Sample

1.2. Tools: Qualitative and quantitative needs assessment $\ldots \ldots \ldots$

1.2.1. Quantitative needs assessment: Questionnaire ………. 7

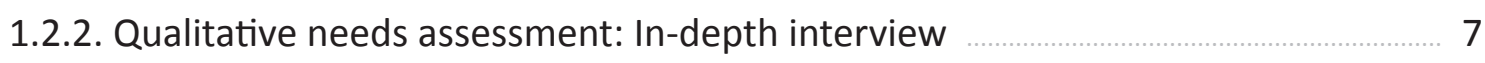

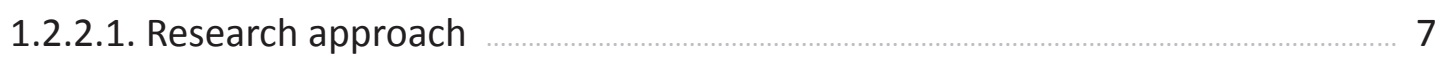

1.2.2.2. Sample $\ldots 10$

2. In-depth interviews: working with traumatized population affect

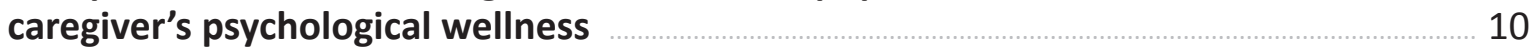

2.1. Caregiver's identity-status and region of work: preliminary indicators _................... 11

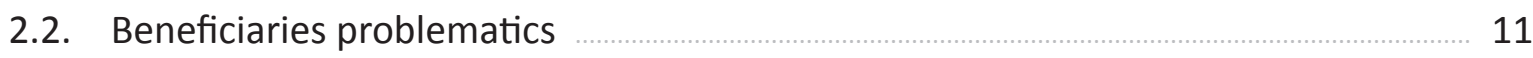

2.3. Psychological impact and trauma transmission …................................................ 11

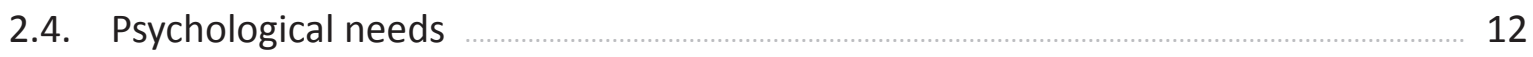

3. New research perspectives $\ldots 14$

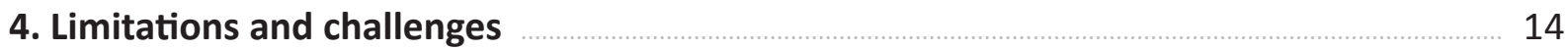

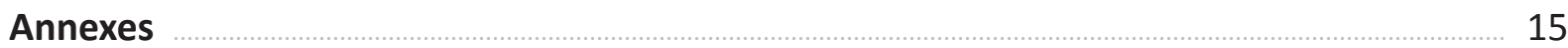

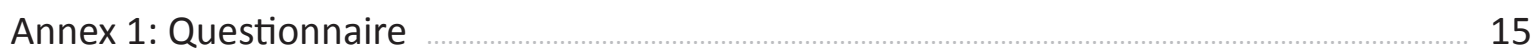

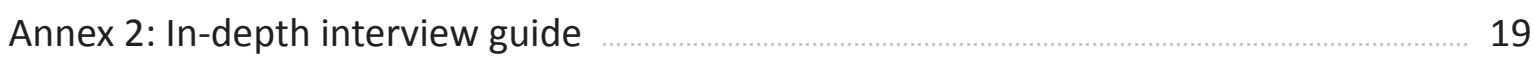

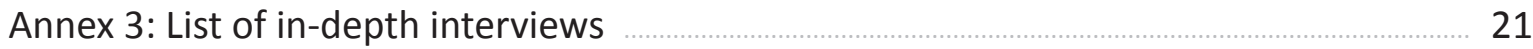




\section{Foreword}

This study was conducted in November and December 2016 throughout collaboration between the Arab Resource Collective-ARC and Lebanon Support-LS. In this vein, Lebanon Support contracted a team of 4 Psychologists experts.

The Arab Resource Collective is developing a strategy for a web-based Mental Health and Psychosocial Support-MHPSS knowledge hub for caregivers working with refugees in fragile contexts in the Arab region. This regional MHPSS knowledge hub would aim at pooling and expanding the resources in Arabic that help to empower and increase the human capital of MHPSS caregivers involved mainly in the Syrian refugee crisis. The hub would compile materials in Arabic and make the content accessible and adapted to the Arab contexts where the MHPSS caregivers are in need of relevant information and resources in Arabic. An English section will also be available.

In order to conduct a study that assesses the psychological needs of the caregivers working with Syrian Refugees ARC contracted Lebanon Support that subcontracted a team of psychologists' experts. The objective was to assess the needs that will be sorted in the MHPSS knowledge hub.

Lebanon Support is an independent non-governmental, non-religious, non-political, and non-profit making information and research center, established in Lebanon in 2006. LS aims at enhancing civil society capacity, efficiency and effectiveness through the creation of public spaces for reflection, collaboration and debate on and for civil society in Lebanon. LS's multidisciplinary approach and evidence and fact based methodologies in civil society work in Lebanon seeks to support and develop a civic voice, and work towards better accountability and societal change.

The Arab Resource Collective (ARC) is a regional non-governmental organization, established in 1988. To achieve better childhood, health for all and community development, ARC pursue the translation into reality of the rights of Children and youth to health, education, protection and participation, in their ecological community environment in the Arab world. Along with partners, ARC strives to build the culture and practice tools of knowledge production, to develop human resources, to enhance participation, and to promote networking and advocacy.

In the framework of this project, a team of four psychologists has been hired by LS. This team of experts has been working since 2006 as international and local NGOs consultants, psychotherapists with refugees and supervisors for mental health caregivers in refugees' camps.

Nathalie Der-Sahaguian Ayvazian is a clinical psychologist and a psychotherapist, NGO consultant and the head of counseling and guidance department in Eduvation school network.

Dr Mayssa' El Husseini is a clinical psychologist, a psychoanalyst and a family psychotherapist at Hôpital Cochin Paris, a INSERM researcher, Médecins sans Frontières consultant and a lecturer at Paris Descartes, coordinator of the seminar: Psychological Support in Humanitarian Missions.

Rose-Marie Nassif Abou Assaf is a clinical psychologist, a psychoanalyst, member of Association Libanaise pour le Développement de la Psychanalyse ALDeP, and a counselor at Eduvation school network.

Zeina Zerbé is a clinical psychologist and a psychoanalytic psychotherapist, a lecturer at Saint-Joseph University of Beirut, project consultant for Pontifical Mission and Joint Christian Committee-JCC and support group facilitator for women and youth in Dbayeh camp for Palestinian refugees'.

https://lb.linkedin.com/in/zeina-zerbé-5003b23 


\section{Objective of the Study and Experts' roles}

As mentioned in the foreword, the purpose of the needs assessment and strategy development for a Web-based knowledge hub is to identify what is needed the most and what works best for the future building of a MHPSS Knowledge Hub (KH).

Thus, to assess the caregivers' needs, the psychologist experts were in charge of:

- Reflecting and developing a closed questionnaire that was posted online;

- Developing an open questionnaire that defines the body of the in-depth interview;

- Conducting the in-depth interviews with the key MHPSS actors, experts and fieldworkers;

- Crossing, analyzing the results and sorting the findings;

- Presenting and discussing the primary findings with the MHPSS professionals during ARC Regional Consultative Workshop;

- Generating the current qualitative report. 


\section{Methodology}

\subsection{Sample}

In order to obtain relevant data to support the construction of the $\mathrm{KH}, \mathrm{ARC}$ mapped the actors in need for such a tool. In this vein, both the questionnaire and the in-depth interviews targeted the candidates who are working with Syrian, Palestinian and Iraqi refugees in the Arab Countries.

Targeted candidates consisted of mental health experts (consultants, field workers), psychosocial actors, technical coordinators, social, political sciences experts, medical experts, administrators and logisticians. Moreover, candidates were involved in governmental institutions, international and local NGOs, but also as freelancers or volunteers.

The security situation of the region in which the candidates worked was an important factor to take into consideration, as the study not only targeted to examine candidates working in relatively safe and stable environments as Lebanon, Jordan, Egypt or Irbil but also those working in regions exposed to war, terrorists attacks, checkpoints or a high risk of kidnapping like Syria and Palestine. Otherwise, the candidates' status whether they are local experts, internally displaced or refugees was an important variable to examine in order to determine eventually personal factors of psychological vulnerability. Moreover, the study has included expatriates in order to understand their needs and to target them with specific recommendations that could help them working in the Arab region ${ }^{(1)}$.

\subsection{Tools: Quantitative and qualitative needs assessment}

In order to identify the psychological needs of caregivers working with Syrian refugees, a questionnaire and in-depth interview guide were developed. This guide encompassed all possible -personal and professional- problematics encountered on the field which could affect the caregivers' psychological wellness. Hence, the team of experts aimed to assess and link, throughout both, the quantitative questionnaire and the in-depth interview, the candidates' personal information, their work conditions and specificities, the psychological impact generated by the situation on the field, and the population they are working with. This has been done in order to be able to define, with the candidates, their psychological needs.

In a second phase, the objective was to cross and to analyze the qualitative results and emergent themes of the in-depth interview with the quantitative results of the questionnaire. The results of the in-depth interview aimed to nuance and add a level of complexity to the results highlighted by the questionnaire.

\subsubsection{Quantitative needs assessment: Questionnaire ${ }^{(2)}$}

The questionnaire was developed as a closed survey revolving around the following categories:

I. Personal information, professional work setting and conditions

II. Psychological Impact

III. Identifying the psychological needs

It was uploaded and published online in both English and Arabic versions and remained online between the $25^{\text {th }}$ of October 2016 and the $25^{\text {th }}$ of November 2016.

148 participants have participated to the survey. $77 \%$ of them are female and $23 \%$ male. $48 \%$ are between $20-29$ years old, 39\% between 30 and 39 years old, $9 \%$ are between 40 and 49 years old and only $4 \%$ are above 50 years old. Besides, $64 \%$ of the sample is single, $31 \%$ is married and $5 \%$

1. ARC had raised a concern regarding issues related to non-Arab caregivers' communication and standards as ARC had already noted, during their practice, communication gaps/difficulties between the "western» MHPSS, the donor community and the psycho-social community in the Arab World.

2. For details on the quantitative questionnaire see annex 1. 
is divorced. Therefore, the data relative to the current survey indicates that mainly young single women are involved in the psychosocial and humanitarian sector.

Regarding their nationality, $63 \%$ of the participants are Lebanese, $11 \%$ are Syrian, $9 \%$ are Egyptian, $6 \%$ are Palestinian and $4 \%$ are French. $82 \%$ of them work in Lebanon and $12 \%$ work in Egypt according to the main results. 59\% indicate working in relatively safe and stable regions, $22 \%$ in regions exposed to terrorists attacks and $19 \%$ in region exposed to war; this is because, if we look closer to the field security situation in Lebanon, the different lebanese regions are not considered equally safe. Beirut for example is considered safer than regions as Ersal exposed to terrorist attacks or borderlines regions exposed to Syrian war.

$70 \%$ of the participants are local experts, $13 \%$ are expatriate, $13 \%$ are refugees and $4 \%$ are internally displaced. Among them, 57\% are involved in local NGO, $31 \%$ in international NGO and only $5 \%$ in governmental institutions. This testifies how poor is the government involvement in the Syrian refugee crisis and that local and International NGOs are mainly the ones who are responding to the refugees' needs. Furthermore, we mention that $6 \%$ of the contracts were signed in $2012,8 \%$ in 2013 , $10 \%$ in 2014, 21\% in 2015 and 55\% in 2016 which reveals (regardless of the fact that maybe only newly hired people have participated to the survey) the increase of the needs and more involvement of L-NGO and INGO across the mentioned years.

Concerning the targeted population of refugees, $30 \%$ of the participants are involved with children, $25 \%$ with teenagers, $20 \%$ with women -mainly suffering from GBV-, $19 \%$ with parents and only $6 \%$ with elderly. The listed population suffers from psychological problems (34\%), misery and precarity $(27 \%)$, trauma of war (22\%), death (7\%) and missing (6\%) of beloved ones and scars-mutilation or amputation (4\%).

Thus, the work with refugees affects personally and psychologically the humanitarian actors. Among psychosomatics symptoms, 37\% reported suffering from fatigue, $21 \%$ from headaches, $14 \%$ from stomach aches, $10 \%$ from agitation, $9 \%$ from difficulty in breathing. Besides, they reveal being affected by vivid remembrance and flashbacks of sensory images related to what they saw (56\%) on the field and to what they heard (36\%). Related to mood change, $23 \%$ of them have noted being more irritable, $23 \%$ having an excess in energy (mania?), $22 \%$ feeling anger and $14 \%$ crying easily. Related to behavioral change, $28 \%$ of them have noted sleep changes, $17 \%$ appetite changes, $13 \%$ increasing in smoking habits, $13 \%$ agitation, $10 \%$ social isolation, $3 \%$ resorting to psychoactive substance. Thereby, humanitarian actors seem to feel overwhelmed and need instantly technical and psychological support.

Even though $78 \%$ of them mentioned having received a training before starting their work, -only $68 \%$ among them believed this training was helpful-, many reported having encountered situations in which they felt they didn't have the tools to deal with because the situation's' needs did not meet their expertise $(13 \%)$, or because the lack of training $(16 \%)$, the lack of resources $(34 \%)$ or because the situation was too overwhelming psychologically and refugees were suffering from severe distress (24\%). Some of them (9\%) said they were faced with defiance and/or mistrust.

To improve the quality of their work, $60,4 \%$ of the participants ask for psychological support such as technical supervision, personal psychological support and being a part of a support group, 70,8\% ask for technical support such as new tools to intervene, resources, coordination and collaboration with other partners and $12.5 \%$ need trainings.

Unfortunately, the sample that responded to the questionnaire is mainly limited to Lebanese caregivers and-or to expatriate and refugees humanitarian actors working in Lebanon. Nor Jordanian or Turkish or Iraqi have participated to the study and among the Syrian who did, just $1 \%$ of them work in Syria. Thus, the sample doesn't represent all the categories we target to a larger understanding of $\mathrm{MH}$ workers involved in the Syria crisis and we cannot generalize and consider the results as representative of the $\mathrm{MH}$ caregivers work conditions and needs in the Arab region. 


\subsubsection{Qualitative needs assessment: In-depth interviews ${ }^{(1)}$}

The in-depth interview was developed to allow an open association of thoughts following a semistructured interview guide. "The aim of the interview is largely to facilitate an interaction which permits participants to tell their own stories, in their own words» ${ }^{(2)}$. The interviews' grid was based on open questions targeting the main axis of the study's objectives: assessing the psychological impact of work with refugees on humanitarian aid actors and identifying the needs for psychological support. Below the axes tackled-same as the one leading the questionnaire:
I. Personal Information
II. Work conditions and specificities
III. Psychological Impact
IV. Psychological Needs

\subsubsection{Research approach}

In-depth interviews were mainly done via skype; each lasted between one hour and one hour and a half. Interviews were recorded and transcribed, then analyzed using the interpretative phenomenological analysis (IPA) methodology ${ }^{(3)}$.

The interview design was based on literature review as well as on the results of a research conducted by Dr Mayssa' El-Husseini(4) between 2013 and 2016 focusing on the impact of trauma clinic on therapists. The results of Dr Husseini's research highlighted the implication of several variables within the impact of humanitarian work with a population fleeing war, struggling with precarious living conditions and having potentially traumatic experiences:

- The regional context: instability (security restrictions, risk of terrorist attacks, risk of kidnapping etc.) and war zones (ongoing shelling or armed conflicts);

- The work setting: institutional conflicts, access to supervision and psychological support;

- The cultural gaps: cultural differences between the expatriates and the field of work, and beneficiaries; between the institution and the local humanitarian staff; political stances and religious differences between humanitarian actors and beneficiaries etc.;

- The exposure to the beneficiaries' traumatic experiences narratives;

- The exposure to the precarious reality of the beneficiaries and the gap between the humanitarian actors' conditions and those of the beneficiaries etc.

Therefore, the questions were based on previous research results and were treated as guidelines in the conception of the interview grid. However, the interviewers were guided by the narratives of the participants. The interview guide was based on the following types of questions: descriptive, narrative, structural, contrast, evaluative, circular, comparative, prompts and probes. The data collected through open interviews provided us with the themes that emerged from the participants regarding our topic.

1. For details on the in-depth interviews see annex 2 .

2. Jonathan A. Smith, Paul Flowers, Michael Larkin, Interpretative phenomenological analysis: Theory, method and research, London, Sage, 2009, p 57.

3. IPA tends to explore an individual's personal perception or account of an event or state. IPA is concerned with trying to understand lived experience and with how participants themselves make sense of their experiences. Therefore it is centrally concerned with the meanings which those experiences hold for the participants.

4. Mayssa' El Husseini, Exploration du contre-transfert dans la clinique du trauma, une étude qualitative, 25 Janvier 2016; Mayssa' El Husseini, Sara Skandrani, Layla Tarazi Sahab, Elizabetta Dozio and Marie Rose Moro, "Countertransference in Trauma Clinic: A Transitional Breach in the Therapist's' Identity», in Ghassan El-Baalbaki, Christophe Fortin, A Multidimensional Approach to Post-Traumatic Stress Disorder-from Theory to Practice, 2 November 2016, available at http://www.intechopen.com/books/a-multidimensional-approach-to-post-traumatic-stress-disorder-from-theoryto-practice/countertransference-in-trauma-clinic-a-transitional-breach-in-the-therapists-identity [last accessed 27 december 2016]. 


\subsubsection{Sample}

The interviews were conducted with participants selected throughout purposive sampling: the humanitarian actors working with refugees in 6 regions in the Middle East were identified by ARC. The participants were considered experts in their respective fields.

In order to be the more representative of the caregivers needs, the sample aimed to gather individuals working in governmental institution (Gov.), international NGO (INGO), local NGO (LNGO) and Syrian NGO (SNGO) spread all over 7 countries in the Arab region. However, ARC faced many constraints in meeting the initial quotas and distribution targeted, especially in finding interviewees in Turkey which lead to the exclusion of Turkey from the research.

The first table below indicates the initial quotas and distribution of the population targeted by the study; the second one summarizes the final distribution of the sample.

Table 1: MHPSS professionals per country: Initial Quotas and Distribution Targeted

\begin{tabular}{|c|c|c|c|c|c|}
\hline & Total no. & Gov & INGO & S-NGO & LNGO \\
\hline Lebanon $^{(1)}$ & 10 & 1 & 2 & 3 & 4 \\
\hline Jordan & 4 & 1 & 1 & 1 & 1 \\
\hline Syria & 3 & & & & 3 \\
\hline Egypt & 2 & 1 & & & 1 \\
\hline Palestine & 3 & 1 & & & 2 \\
\hline N. Iraq & 2 & & 1 & & 1 \\
\hline Turkey & 4 & 1 & 1 & 1 & 1 \\
\hline Total & $\mathbf{2 8}$ & $\mathbf{5}$ & $\mathbf{5}$ & $\mathbf{5}$ & $\mathbf{1 3}$ \\
\hline
\end{tabular}

Table 2: Final Distribution of the sample

\begin{tabular}{|c|c|c|c|c|c|}
\hline & Total no. & Gov & INGO & S-NGO & LNGO \\
\hline Lebanon & 5 & & & & 2 \\
\hline Syrians in Lebanon ${ }^{(2)}$ & 5 & & 1 & 1 & 3 \\
\hline Jordan & 4 & & 1 & & 3 \\
\hline Syria & 4 & & 2 & & 2 \\
\hline Egypt & 2 & & 2 & & \\
\hline Palestine & 3 & & 1 & & 2 \\
\hline N. Iraq & 2 & & & & 2 \\
\hline Expatriates & 3 & & 3 & & \\
\hline Total & $\mathbf{2 8}$ & $\mathbf{1}$ & $\mathbf{1 2}$ & $\mathbf{1}$ & $\mathbf{1 4}$ \\
\hline
\end{tabular}

\section{In-depth interview: working with traumatized population affects caregiver's psychological well being}

The results below represent the main findings of the qualitative part. They were organized under the four main axes tackled by the research. Therefore, we started to explore the interviewee personal

1. 5 Lebanese working with Syrian refugees and 5 Syrian, working with Syrian refugees.

2. Syrians in Lebanon: 4 Syrians working with Syrian refugees and 1 Palestinian working with Syrian refugees. 
information, the effect of the work conditions and specificities on him or her and the psychological impact of his or her professional interventions with the affected communities and individuals. Thus, we were able during the last phase of the interview to extricate and determine with the candidates their psychological needs.

\subsection{Caregiver's identity, status, and region of work: preliminary indicators}

The first finding is that the nationalities and the countries of origin of the interviewees, the regions they are working in and their current status -whether they were local experts, internally displaced, refugees or expatriates- are directly affecting their motivation in working with refugees and their psychological well-being. For example, a Palestinian whose parents were displaced in 1948 from the district of el-Khalil and who is currently working in Ramallah is considered both as a refugee and a local expert. His motivation to work with refugees is: the national duty, the feeling that the Palestinian refugees are his people and that their cause is his cause. A Syrian coming from El Houleh and working in Damascus is also considered as a local expert internally displaced. His motivation to work with refugees is the national duty, the need to do something for his people and to fight the feeling of impotence.

Thus, the psychological mindset of Palestinians working in Palestine and Syrians working in Syria is different from the psychological mindset of Lebanese, Jordanian and Egyptian mental health workers working with Syrian refugees in their respective countries as they are not personally -physically, psychologically, socially and politically- affected by the war or the occupation.

\subsection{Beneficiaries problematics}

We noted also that the degree of security of the region of work affects psychologically the mental health $(\mathrm{MH})$ workers. Thereby, people working in relatively safe regions are less stressed and feel safer than people working in regions exposed to terrorist attacks, unexpected armed invasion, armed confrontation, unexpected houses destruction, illegal detention, risks of kidnapping, ongoing shelling, instable war zones to cite only a few. In Syria and Palestine for example, MH caregivers are stopped, on their way to work, at several checkpoints and are controlled by soldiers or militia men with the possibility of being subject to power abuse.

These incidents may affect their ability to be on time at work and disturb their capacity to concentrate. They become more vulnerable and are often exposed to the same issues as the beneficiaries they are taking care of.

Besides, the research indicates that mental health workers are usually more affected than technical coordinators or a logisticians working with refugees. The $\mathrm{MH}$ caregivers are more exposed to the beneficiaries' issues and narratives which may lead them to feel overwhelmed because of the load of work and their inability to cover all people's needs. The interviewees expressed having a lot of pressure since the demands often exceed their capacity to respond especially that the number of professionals available on the field is not sufficient.

\subsection{Psychological impact and trauma transmission}

In order to assess the psychological impact of the work with refugees on the MH caregivers, we will examine on one hand the problematics of the beneficiaries they are working with and on the other hand the way they get affected by trauma and precarity. This will help us to assess the interviewee's' level of coping and functioning and to evaluate the level of psychosocial impairment in order to sort with them their psychological needs. 


\section{THE BENEFICIARIES' ISSUES AND SPECIFICITIES:}

The interviewed caregivers work mainly with children, women and families that are either displacedinternally displaced or refugees exposed mostly to poverty and precarity. These beneficiaries suffer from many problematics. Some of them have been exposed to death, massacres, loss of dear ones, loss of their belongings, house destruction, family scattering, couple separation; some have a missing, kidnapped or imprisoned family member; some have scars, mutilation or amputation and suffer from disabilities due to armed aggression or shelling; all of them suffer from depression, anxiety, sleeping troubles and some of them have communicated suicidal thoughts; many suffer from Gender Based Violence-GBV; we mention especially the early marriage for girls; some are orphans; many suffer from school drop or lack of education; many children suffer from abuse, incest, pedophilia.

\section{THE PSYCHOLOGICAL IMPACT ON THE MH CAREGIVERS:}

The interviewees mentioned being personally affected by the beneficiaries' narrative and situation. Thus, they reported having physical reactions themselves: breathing difficulties, migraine, stomachaches, vicarious traumatization -feeling the patient's symptoms-, chronic fatigue and lack of energy, insomnia, hair loss, more wrinkles and feeling of being older than their actual age, physical agitation to cite only a few. The persistence and gravity of the symptoms varies upon the interviewee's personality and the degree of exposure to the beneficiary's trauma.

Thus, they reported also the emergence of many images that are impairing their daily functioning such as intrusive vivid imageries, the remembrance of the patient's discourse and nonverbal attitude: the voice, the look, the body shaking etc. They reported being exposed to flashbacks and recurrent thoughts. According to the Syrians and the Palestinians interviewees, the images of the destructed cities -the images of the city before and after the shelling- are often hunting them. Many suffer from nightmares.

Noteworthy to mention here is also their feeling of helplessness, impotence as well as their fear of the future.

Besides, many noticed being more complaining and nagging and having more disputes with their partners and relatives.

\section{THE RESOURCES:}

Among the professional resources that helped the interviewees coping with the situation, we can mention: the satisfaction of doing a great job - the feeling of fulfilling a mission; beneficiaries' grateful reactions and feedbacks; clinical, technical, peer supervision; colleagues' support groups; trainings; psychotherapy.

Among the personal resources that helped the caregivers coping with the situation, many consider their spouse or partner as a great support, their family, as well as religious faith. The family is described as an important support. It offers the interviewee a great understanding and listening. Sometimes, the spouse helps out with the housework when caregivers are on the field. This is much appreciated especially by women caregivers.

The religious faith help provides them with security and feeling of trust.

As for their hobbies, interviewees cited activities such as going to the beach, participating to outings, doing sports, yoga, meditation and travelling. The activities help them to interrupt daily work routine and to regain energy in order to be able to go back to work with more motivation and less load. Having access to activities prevents also from burn out.

\subsection{Psychological needs}

Many needs have emerged and need to be taken into account in order to allow the $\mathrm{MH}$ caregivers to keep on providing their services with the least psychological damage possible: 


\section{NEEDS RELATED TO INSTITUTIONAL FUNCTIONING:}

The $\mathrm{MH}$ interviewees expressed the need of redefining the relationship to the institution or I-NGO directors and funders. They believe that the in-depth cultural and political aspects should be further explored before implementing the projects and activities. Many expressed the need to be heard by funders and directors that often intervene- according to a $\mathrm{MH}$ provider- with a "colonial superiority" and implement activities without acknowledging the expertise of local professionals. Along with this, directors are more often concerned about objectives, results and numbers and do not heavily weight the reality on the ground, the beneficiaries' personal pace and needs, the caregiver's response to trauma and the caregiver's psychological well-being.

The $\mathrm{MH}$ providers were also concerned about sustainability of the programs that are often cut because of short term funding. This causes frustration, psychological and financial insecurity to the professional that has also the feeling of being forced to leave the fieldwork and the projects with work unfinished.

Besides, the physical security of the mental health worker who intervenes on the field without any physical protection is expressed as a real issue. The MH suggested for example, that NGOs' directors assure contacts with the related government, work on providing them with a pass and on guaranteeing their evacuation in case of attacks.

Furthermore, many expressed the need of ensuring partnership with other NGOs in order to cover all the beneficiaries' needs. For example NGOs contracting lawyers or Cheikh expertise for GBV cases 'protection, MD expertise for people with disabilities etc.

Regarding the job assignments, interviewees insisted on predefining a clear job description. They reported that many times functions and roles overlap which create confusions for the $\mathrm{MH}$ provider and problems related to task assessment. It happens when there are a lot of demands that the mental health professional intervenes in many domains such as trauma, Gender Based ViolenceGBV etc. which provokes a dispersion of his functions and encourages a more general rather than specialized approach.

Adjusting one's salary also provides the $\mathrm{MH}$ caregiver with security reduces financial stress and gives access to better lifestyles. Improving also the work conditions and settings as providing the mental health workers with extra days off were required to reduce work pressure; giving them access to a private office was required for more efficiency and better concentration.

Besides, many expressed the difficulties of supervising and accompanying volunteers or freshly graduated people who are -despite their goodwill- described as often not efficient, easily more affected and coping less while dealing with beneficiaries. Thus, interviewees asked for hiring a professional team, especially during severe humanitarian crisis, for better productivity.

As for the expatriates, they asked for the institution or I-NGO support once confronted to critical decisions to take on the field. Sometimes they have the feeling to be left alone and experience a serious gap between the hub's concerns and the reality of the emergencies on the field.

\section{REGARDING THE PROFESSIONAL SUPERVISION AND COACHING:}

The $\mathrm{MH}$ interviewees expressed the need to benefit from continuous trainings such as trainings on trauma and psychosocial modalities of intervention. Besides, they highlighted the lack of formations adjusted to the emergence of new problematics such as disabilities, special needs due to war conflicts, addiction, drugs addiction, development disorders, psychosocial rehabilitation of the political prisoners etc. Thus, there is a need of continuous evaluation of the field new requirements.

Moreover, creating a manual of evaluation and intervention techniques that take into consideration the local cultural specificities would be very helpful. The $\mathrm{MH}$ caregivers were complaining about abiding by translated manuals that propose psycho-intervention techniques that don't apply to the local and cultural specificities.

Continuous supervision -once per week or once every two weeks- amongst which clinical, technical and pear supervision was required as a necessary condition for good working. Supervision helps the 
professional to study the cases with distance and to reflect on the fieldwork throughout theoretical approach. It provides him or her with support and also protects the patient from therapist's blind spots.

Psychotherapy is an important need and helped a lot the ones who have benefitted from it. Financial issues prevent the professionals in need to undertake the move. $\mathrm{MH}$ caregivers suggested that institution takes in charge a part of psychotherapy financial charges for the ones in need.

\section{New research perspectives}

During field work, topics of research emerged that could serve as suggestions for further researches; among them the work for memory. Since the war has started in the Arab region, related data hasn't been collected. Information related to destruction, name of people dead, kidnapped, missing is recommended to be transcribed. Psychological and social strategies of coping should be observed, analyzed and reconsidered in order to develop later studies related to the crisis or the phenomenon. Regarding the emergence of new psychological impairments, new cases, particular demands and psychosocial interventions conducted accordingly should be noted in order to conduct further researches -related to the crises- that align theories and field study.

The identity issue is also a problematic we should lean on. The conception of personal identity is evolving among the population exposed to war, trauma and displacement. Displaced people and refugees have reported feeling disturbed regarding their nationality. For example, being Syrian, before war, has always been a pride. The new status of being a Syrian refugee waiting for social aid generates humiliation, insecurity and precarity. How does the Syrian people deal psychological and self-represent their Syrian identity? How do they cope with the rejection they are facing worldwide among other populations and extreme right-wing policy? Could it lead them to violence and consequently to more marginalization?

Thus, population hosting refugees' reported feeling threatened. Refugees are pointed as a burden and national identity is brandished. It would be interesting to reflect on the effect of the presence of the refugees on one's identity and belonging.

This led us to lean on the phenomenon of mixing and integration that the hosting countries witness. Lebanon and Jordan are hosting Syrian, Palestinian and Iraqi refugees that became integrated and at the same time marginalized components of the Lebanese and Jordanian societies. Thus, observing and analyzing the evolvement of the social composition of the Arab countries is a study that it would be interesting to conduct, taking into consideration the governmental politics and law regarding refugees and the psychosocial reaction of local population.

\section{Limitations and challenges}

The study confronted many limitations and challenges. According to the in-depth interview, in order to meet the number of interviewees required, ARC had to recruit candidates -in Egypt, North Iraq and Lebanon- working in the same NGO, the same setting and working conditions, intervening with the same population. This has generated redundant responses. Thus, the sample related to the listed countries was less varied than expected.

The time frame imposed to conduct the research was too tight. The 28 interviews, the transcription and the research were conducted during the month of November 2016. Such research needs much more time to be thorough.

According to the questionnaire, $70 \%$ of the candidates who answered the Survey Monkey's questionnaire are Lebanese, $93 \%$ are living in Lebanon and $82 \%$ are working in Lebanon. Thus, we were unable as developed above to cross the results of the in-depth interview with the results of the questionnaire; the results of the Survey Monkey represents mostly the needs of the people working in Lebanon and do not reveal the ones related to the 6 other countries targeted by the study. 


\section{Annexes}

\section{Annex 1}

\section{QUESTIONNAIRE}

I. Personal information, professional work setting and conditions

1. Age

2. Sex

3. Marital Status:

- Single

- Married

- Divorced

- Widowed

4. Do you have children?

- Yes

- If yes how old are they?

- No

5. Religious views

6. Nationality

7. Country of origin

8. Current country of residency

9. Region of work

10. Safety conditions: how would you describe the region you are working in

- Safe-stable

- Exposed to war

- Exposed to terrorist attacks

11. Describe your current status:

- Expatriate

- Internally displaced

- Refugee

- Local expert

12. Did you have to leave your partner/family/children?

- Yes

- No

13. Professional background/Major

14. Employer:

- Governmental institution

- International NGO

- Local NGO

- Freelancer

- Volunteer 
15. Describe the duration of your contract:

- Date of the beginning

- Ending date of the contract:

16. Have you done previously a humanitarian work/mission?

- Yes

If yes: Location

Type of mission

- No

17. What has motivated you to work with Syrian refugees?

- The humanitarian cause

- The job opportunity

- Personal/Family being also victim of injustice

- Other (precise)

18. Work Schedule

- Part time

- Full time

19. Professional status

- Mental health expert-Consultant

- Mental health field worker

- Psychosocial actor

- Logistics

- Administrator

- Medical staff

- Other (precise)

20. Describe the main beneficiaries of your mission

- Children

- Teenagers

- Women/Adults

- Elderly

- Parents

21. Describe the main domain of intervention of your mission/organization:

- Health-Medical needs

- Mental Health-Psychological support

- Psychosocial-GBV

- Psycho legal

- Social aid (distribution of food, clothes etc.)

- Other. Precise

22. Describe where you work

- In an office

- In an office located in a shelter/Refugee camp

- Open space/No office

II. Psychological Impact

23. Do you believe there is a cultural/social/political gap between you and the population you are working with?

- Yes - Develop

- No 
24. If yes, how does it affect your work?

25. While intervening, what are the major issues you are exposed to?

- Misery and precarity

- Scars/Mutilation/amputation

- Kidnapping/Missing people

- Death

- War stories

- Psychological problems

26. How do you feel about it?

- Anxious

- Guilty/Shameful

- Horrified

- Repulsive

- Powerless/Helpless? Impotent

- Sad/despaired

- Fearful

- In rage

- Indifferent/detached

- Wanting to avoid the contact

- Empathetic

- Eager to help and find solutions

27. Do you sometimes feel like you have difficulties to think or to find your words facing some situations?

- Yes

- No

28. During your mission, did you notice any personal physical reactions?

- Agitation

- Fatigue

- Headaches

- Stomach aches

- Difficulty in breathing

- Other

29. According to your five senses, what makes the remembrance of your experience the more vivid?

- What you saw

- What you heard

- What you smelled

- What you tasted

- What you touched

30. Do you spontaneously have sensory images or scenarios when you listen to the narration of the refugees (sensory images can be visual with impressions of sounds, smells, movement)?

- Yes

- No

31. Since you have started your mission, did you notice any mood changes?

- Irritability

- Crying easily

- Anger

- Excess in energy

- Other 
32. Since you have started your mission, did you notice any behavioral changes?

- Social isolation

- Agitation

- Resorting to psychoactive substances (alcohol, medication, other substances)

- Increase in smoking habits

- Sleep changes

- Appetite changes

33. What are the resources that help you coping with the situation?

- Psychological (professional) support

- Colleagues support

- Family psychological support

- Friends and outings

- Expression through art: poetry/Photography/Music...

\section{Identifying the psychological needs}

34. According to you what might help you coping better with the situation?

- The work conditions, precise: Example: Load of work, schedule, salary, accommodation etc.

- The professional dynamic with the organization you are working with: Example: task assignments, collaboration with other partners, access to referral system for beneficiaries

- The psychological support you would like to benefit from

- Other-precise

35. Did you receive any kind of training before starting to work with refugees?

- Yes - Describe it briefly

- No

36. In case you have received training, do you feel they have been helpful to cope with the issues encountered while working?

- Yes

- No

37. Have you encountered situations in which you have felt you didn't have the proper tools to deal with?

- Yes

- No

38. If yes, Why?

- The situations' needs did not meet your expertise

- Lack of training

- Lack of resources

- The situation was too overwhelming psychologically (ex: severe distress of the persons encountered)

- You were faced with defiance and/or mistrust

- Other:

39. If yes, what did you do?

- You have intervened despite the difficulties

- You kept the issue pending

40. What would you suggest to improve the quality of your work?

- Psychological support: technical supervision, personal psychological support, being a part of a support group

- Technical support: tools, resources, coordination, collaboration with other partners

- Training: specify

- Other 


\section{Annex 2}

\section{IN-DEPTH INTERVIEW GUIDE}

\section{Personal Information}

1. Age

2. Marital Status/family status - explore past and actual configuration through prompts and probes if not mentioned spontaneously (where they are, who is around, family in safe or unsafe place, contact with family if away)

3. Nationality

4. Country of origin

5. Current country of residency

6. Region of work

7. Current status (expatriate/Internally displaced/Refugee/local expert)

8. Professional background/Major

9. Have you done previously a humanitarian work/mission? What can you tell us about these previous experiences?

10. What has motivated you to work with syrian refugees?

\section{Work conditions and specificities}

1. Safety conditions: how would you describe the region you are working in

2. What type of institutions do you work for? How would you describe it (its functioning; specificities; satisfaction in the being a member of the institution; satisfaction of the services provided etc.)

3. What does your job consist of? (position, type of work, load of work and schedule, main population, if the participant has to move around on the field or office work etc.)

4. Since when have you been there (how long are you staying; does the participant have any visibility on the close professional future in the institution or in the mission etc.)

\section{Psychological Impact}

1. What do you think of your mission and job requirements?

2. Can you tell us about the specificity of the population you are working with?

3. Do you feel familiar with the people you are in contact with? (beneficiaries and team)

4. How can you describe the relations between the humanitarian actors and the beneficiaries? (How are the humanitarian actors perceived in the field of intervention? Explore the participant's representation of the surrounding ambiance, his experience of the beneficiaries' representation of his status as a humanitarian actor and as an expatriate or national)

5. (If not mentioned spontaneously in the previous questions) how does it affect you in your daily life and in your work?

6. What do you encounter during your work with the beneficiaries (Misery and precarity-Scars/ Mutilation/amputation - Kidnapping/Missing people - Death - War stories - Psychological problems)? How do you feel it affects you?

7. Do you sometimes feel like you have difficulties to think or to find your words facing some situations?

8. During your mission, did you notice any personal physical reactions?

9. While you interact with the reality of the beneficiaries, witness their hardship, what makes the remembrance of it more vivid? What moves you most?

10. Do you spontaneously have sensory images or scenarios when you listen to the narration of 
the refugees (sensory images can be visual with impressions of sounds, smells, movement)? Any dreams?

11. What are the resources that help you to cope with the situation?

\section{Psychological needs}

1. Did you receive any kind of training before starting to work with refugees? Do you feel they have been helpful to cope with the issues encountered while working?

2. Have you encountered situations in which you have felt you didn't have the proper tools to deal with? If yes, what did you do?

3. Regarding your work conditions, if you were to identify your needs to improve your psychological well-being, what would you think of? (explore: work setting, professional dynamic with the organization, access to referral system for beneficiaries)

4. Regarding the psychological impact of your interventions, what would you suggest to improve the quality of your work? (explore: psychological support, technical supervision, personal psychological support, being a part of a support group/Technical support: tools, resources, coordination, collaboration with other partners/Training) 


\section{Annex 3}

\section{LIST OF IN-DEPTH INTERVIEWS ${ }^{(1)}$}

\section{Lebanon: 5 Interviewees}

1. Female, 35 years old, managing a program in an international organization, Lebanese based in Lebanon. Interview conducted in Arabic by skype on the 1/11/16, interview duration: 51 minutes

2. Female. 34 years old, psychologist in a local NGO, Lebanese based in the south of Lebanon. Interview conducted in Arabic by skype on the 1/11/16, duration 51 minutes.

3. Female. 31 years old, project officer for an international organization, Lebanese based in Lebanon. Interview conducted in Arabic by skype on the 4/11/16. Duration 50 minutes.

4. Female. Didn't give her age. Policy and advocacy officer for the government. Lebanese based in Lebanon. Interview conducted in Arabic by skype on the 11/11/16, duration of interview: 25 minutes.

5. Female. 39 years old. Teacher in an NGO, Lebanese based in a Palestinian camp. Face to face interview conducted in Arabic on the 3/11/16. Interview duration: 35 minutes.

\section{Palestinian Refugee working in Lebanon: 1 interviewee}

1. Male, 47 years, Palestinian NGO director, Palestinian refugee based in Lebanon, face to face interview, conducted in Arabic on the 3/11/16. Interview duration: $1 \mathrm{~h} 14$ min

\section{Syrian working in Lebanon: 4 interviewees}

1. Male, 57 years, Manager of the Health program, Syrian based in Lebanon, Interview conducted in Arabic, by skype on the 9/11/16. Interview duration: 1 h10 min

2. Female, 41 years, Social counselor, Syrian based in Lebanon, Interview conducted in Arabic by skype on the 3/11/16. Interview duration: 1 h15 min

3. Female, 39 years, math's teacher, Syrian refugee based in Lebanon, Face to face interview, conducted in Arabic on the 28/10/16. Interview duration: 1 h10 min

4. Female, 35 years, science teacher, Syrian refugee based in Lebanon, Face to face interview, conducted in Arabic on the 28/10/16. Interview duration: 1 h05 min

\section{Syrian working in Syria: 4 Interviewees}

1. Male, 48 years, psychiatrist-technical officer for Mental Health in Syria, Syrian-Palestinian based in Damascus, interview conducted in Arabic by skype on the 22/11/16. Interview duration: $55 \mathrm{~min}$

2. Female, 33 years, Sociologist, Syrian working in Syria, Skype interview conducted in Arabic by skype on the 11/11/16. Interview duration: 1 h32 min

3. Female; 51 years old; Syrian internally displaced; working in Syria; interview conducted in Arabic by skype on the 5/11/2016. Interview duration: $1 \mathrm{~h}$

4. Female; 51 years; Sociologist PhD; Syrian working in Syria, Syrian Local Association; interview conducted in Arabic by skype on the 5/11/2016. Interview duration: 1 h15 min

1. The individuals interviewed for the in-depth research have signed a written consent form accepting the terms and conditions of the research. 


\section{Palestinian: 3 interviewees}

1. Female, 42 years, clinical psychologist, Palestinian based in Ramallah. Interview conducted in Arabic by skype on the 2/11/16. Interview duration: 55 min

2. Female, 44 years, psychologist-head of the scientific research, Palestinian based in Gaza. Interview conducted in Arabic by skype on the 8/11/16. Interview duration: 1h35 min

3. Female, 39 years, manager of the child and family protection program, Palestinian based in the West Bank. Interview conducted in Arabic by skype on the 11/11/16. Interview duration: 1 h25 min

\section{Jordanian: 4 interviewees}

1. Male, 40 years old, project manager of educational programs, Jordanian from Jordan, interview conducted in Arabic by skype on the 22/11/2016. Interview duration: 1 hour

2. Female 35 years old. Project manager of a family center, Jordanian based in Amman, interview conducted in Arabic by skype on the 27/11/2016. Interview duration: 1 h15 min.

3. Female 56 years old, executive director of a center working with disabilities, Jordanian based in Amman, interview conducted in English by skype on the 22/11/2016. Interview duration: $1 \mathrm{~h}$.

4. Female 29 years old, divorced, project officer in Advocacy platform, Jordanian based in Amman, interview conducted in Arabic by skype on the 26/11/2016. Interview duration: $1 \mathrm{~h} 30 \mathrm{~min}$.

\section{Egypt: 2 interviewees}

1. Male 40 years old, project manager in a family center, Egyptian based in Cairo. Interview conducted in Arabic by skype on the 31/11/2016. Interview duration 50 min.

2. Female 29 years old, Psychologist, trainer in an INGO, Egyptian based in Cairo, interview conducted in Arabic by skype on the 1/11/16. Interview duration: 53 minutes

\section{North Iraq: 2 interviewees}

1. Male, 40 years, responsible of logistic and delivery services. Kurdish from Iraq, based in Irbil, interview conducted in English by skype on the 29/10/2016. Interview duration: $1 \mathrm{~h}$.

2. Male 40 years old, Project manager of mental health program, Kurdish from Iraq, based in Irbil, interview conducted in Arabic by skype on the 29/10/2016. Interview duration: $50 \mathrm{~min}$.

\section{Expatriates: 3 interviewees}

1. Female, 31 years, Regional manager in an American NGO, Lebanese expatriate working in Turkey, interview conducted on skype, in Arabic, French and English; interview duration: $1 \mathrm{~h} 30 \mathrm{~min}$.

2. Male, 34 years, monitoring and evaluation for projects implemented among the Syrian refugees population; region: Beqaa, Mount Lebanon; Beirut, Italian expat living and working in Lebanon; INGO; Interview conducted in English and French, by skype on the 19/11/16. Interview duration: $3 \mathrm{~h} 10 \mathrm{~min}$

3. Female, 34 years old. Delegate and manager of a program for an international organization. French expat based in Lebanon. Interview conducted in English by skype on the 23/11/16. Interview duration: 37 minutes. 